\title{
How Health Care Providers Can Use Digital Health Technologies to Inform Human Papillomavirus (HPV) Decision Making and Promote the HPV Vaccine Uptake Among Adolescents and Young Adults
}

\author{
Versie Johnson-Mallard, ${ }^{1, *}$ Gabrielle Darville, ${ }^{2}$ Rebeccah Mercado, ${ }^{3}$ Charkarra Anderson-Lewis, ${ }^{4}$ and Jann Maclnnes ${ }^{5}$
}

\begin{abstract}
High-risk stains of human papillomavirus (HPV) is linked to causing cancer, is highly prevalent, and has increased incidence among adolescents and young adults. However, vaccination rates are low. Health care provider recommendation is the biggest influencer toward vaccine uptake. Since more health care providers are using digital health technologies in their medical practices, this study investigated the feasibility of technology to increase informed decision making. A convenience sample of 210 students completed an online survey. Participants were 18-25 years of age (88\%), female (85\%), Caucasian (60\%), and never been diagnosed with HPV (92.9\%). Overwhelmingly, participants owned a smartphone (98.9\%) and used mobile apps for health/health tracking (65.5\%). However, only $29.3 \%$ indicated that they received text messages from their health care provider. Digital health technology can be a cost-effective way for increasing HPV knowledge, removing barriers, and increasing vaccine uptake. Health care providers should explore using various platforms to empower their health care decision making.
\end{abstract}

Keywords: HPV; preventive health; vaccine

\section{Introduction}

Human papillomavirus (HPV) infection is the most common sexually transmitted infection (STI) in the United States and is responsible for $99 \%$ of all cervical cancer cases worldwide. ${ }^{1,2}$ HPV is also associated with other forms of cancer such as anal, oropharyngeal, vaginal, vulvar, and penile. ${ }^{3,4}$ Although vaccines are available to reduce the risk of infection by several of the most prevalent strains of this virus, immunization rates continue to remain low. The HPV vaccine is a two-dose regimen, a shift from a three-dose regimen in 2016, offering protection to those not completing the HPV vaccine series. Specifically, a two-dose regi- men is recommended for girls and boys starting the HPV series at ages 9 through 14 years, three doses remain for boys and girls starting the HPV series at ages 15 through 26 years. In October 2018, the Food and Drug Administration (FDA) expanded the approved use of the HPV vaccine (Gardasil-9) to include women and men ages 27 through 45 years. ${ }^{5}$ In data from the 2016 National Immunization Survey, only 65\% of adolescent females and $56 \%$ of males initiated the two- or threedose vaccine series with $50 \%$ of adolescent females and $38 \%$ of males completing the series. ${ }^{6}$ Not only are these rates lower than the Healthy People 2020 goal of $80 \%$ vaccination, but there is also a distinct

\footnotetext{
'Department of Family, Community and Health System Science, University of Florida, Gainesville, Florida.

${ }^{2}$ Department of Academic Affairs, College of Public Health, University of Georgia, Athens, Georgia.

${ }^{3}$ Department of Pediatrics in the College of Medicine, University of Florida, Gainesville, Florida.

${ }^{4}$ Department of Public Health, University of Southern Mississippi, Hattiesburg, Mississippi.

${ }^{5}$ Department of Human Development and Organization Studies in Education, College of Education, University of Florida, Gainesville, Florida.

*Address correspondence to: Versie Johnson-Mallard, PhD, FAANP, FAAN, Department of Family, Community and Health System Science, University of Florida, 1225 Center Drive, Gainesville, FL 32610, E-mail: vjmallard@ufl.edu
}

(c) Versie Johnson-Mallard et al. 2019; Published by Mary Ann Liebert, Inc. This Open Access article is distributed under the terms of the Creative Commons License (http://creativecommons.org/licenses/by/4.0), which permits unrestricted use, distribution, and reproduction in any medium, provided the original work is properly cited. 
difference in the number of adolescent males being vaccinated compared with females. ${ }^{7,8}$ This disparity may not only be due, in part, to the 5-year lag in the Centers for Disease Control and Prevention (CDC)'s recommendation for the HPV vaccine in adolescent males (2011) compared with adolescent females (2006), but it may also be attributed to the "feminization of HPV" as a women's problem emphasizing the need for frequent and early recommendations by health care providers to parents of adolescent males in particular. $^{9}$

Current literature highlights the importance of health care providers in increasing vaccine uptake with the most common correlate of HPV vaccination acceptance being a provider's recommendation and the most commonly cited reason for nonvaccination being a lack of provider recommendation. ${ }^{10}$ In a nationally representative survey of parents, those parents with adolescent males more frequently expressed being unsure or not likely to have their child vaccinated against HPV, compared with parents of adolescent females, primarily due to a lack of provider recommendation or knowledge. If providers regularly inform patients and parents about the benefits of the HPV vaccine as a cancer prevention, particularly those who are unsure, as well as distribute reminders to patients who are due for vaccination based on recommended immunization schedules, there is an opportunity to improve HPV vaccine uptake among adolescents. ${ }^{11,12}$

One way providers can better inform patients and parents as well as provide reminders of upcoming immunizations is through the use of technology. Text messaging and smartphone applications (apps) present two areas in new media with potential for use as vaccine uptake interventions. Both technologies are highly accessible and popular worldwide, and their usage is more evenly distributed across divisions of race, class, and international borders compared with other devices and services such as desktop and laptop computers and home broadband. ${ }^{13-15}$

Current literature indicates an increase in the use of text messaging and apps as mobile health interventions, with evidence that these methods have succeeded in reducing missed appointments, educating adolescents about sexual health, and tracking patient information. However, very little existing research has examined the application of these technologies to interventions for HPV vaccine uptake and completion of the two- or three-dose series, demonstrating the need for further inquiry within this area.

\section{Literature Review}

HPV pathology and epidemiology

HPV refers to a group of over 150 related types of a DNA tumor virus that causes abnormal growth and accumulation of epithelial tissue in skin and mucous membranes, ${ }^{1,16}$ More than 40 types of HPV infect the human genital tract and can be transmitted through direct sexual contact, including oral, vaginal, and anal sex. Each of these sexually transmitted types of HPV falls into one of two categories: nononcogenic or lowrisk strains that can cause the formation of skin warts in the anogenital area and the oncogenic or high-risk strains that can cause cervical, anal, oropharyngeal, vaginal, vulvar, and penile cancers. ${ }^{17}$

HPV is responsible for $\sim 90 \%$ of all cases of genital warts, $99 \%$ of all cervical cancers, $95 \%$ of all anal cancers, and $70 \%$ of all oropharyngeal cancers worldwide. ${ }^{1,2,17}$ HPV is the most common STI in the United States, with $\sim 79$ million Americans currently infected and 14 million becoming newly infected every year. The global prevalence of HPV infection in women without cervical abnormalities is $\sim 11 \%$ to $12 \%$, with higher regional rates in sub-Saharan Africa, Eastern Europe, and Latin America. ${ }^{18}$ The worldwide prevalence of HPV infection among males receives little to no coverage in the current literature.

\section{HPV vaccination}

To reduce the risk of HPV infection and its potential health effects, the U.S. (CDC) recommends that individuals use latex condoms during sexual activity, attend routine screenings for cervical cancer if applicable, and receive HPV vaccinations. ${ }^{1}$ The $\mathrm{CDC}$ currently recommends that all children ages 11 to 12 receive two doses of an HPV vaccine 6 to 12 months apart; "catch-up" vaccination is also recommended on a three-dose schedule for females up to age 26 years, males up to age 21 years, transgender adults up to age 26 years, and young adults with immunocompromising conditions such as HIV/ AIDS up to age 26 years. Three noninfectious HPV vaccines are currently approved for use by the U.S. FDA. ${ }^{5}$

The bivalent vaccine Cervarix (2vHPV, manufactured by GlaxoSmithKline in Rixensart, Belgium) targets HPV types 16 and 18, the oncogenic strains responsible for the majority of all HPV-related cancers. The quadrivalent vaccine Gardasil (4vHPV, manufactured by Merck and Co, Inc., in Whitehouse Station, NJ) adds protection from strains 6 and 11, which are responsible for genital warts; its nonavalent counterpart, Gardasil-9 (9vHPV), includes additional protection 
from types $31,33,45,52$, and $58 .{ }^{19}$ In $2015, \sim 62.8 \%$ of females and $49.8 \%$ of males in the United States had received at least one dose of an HPV vaccine; only $41.9 \%$ of females and $28.1 \%$ of males had attained complete vaccine adherence with three or more doses. ${ }^{20}$ An estimated 59 million women worldwide have received at least one dose, making up $1.7 \%$ of the global female population, while 47 million-1.4\%-have received the complete course of the vaccine. ${ }^{21}$ Data on international male HPV vaccine coverage are absent from currently available literature.

\section{Theoretical application}

Digital health technologies, as a cue to action within the health belief model (HBM) as seen in Figure 1, can impact the health decision making among adolescent and newly transitioned college students. ${ }^{22}$ This is especially important when communicating messages about HPV and the HPV vaccine because research has shown that adolescents and college students alike are unaware of their risk of contracting the disease and how the HPV virus can be contracted. Because of this, the purpose of this research study is to determine how health care providers can utilize digital health technologies (such as the internet, mobile phones, short message service [SMS] text messages, and mobile apps) to increase individual risk perception of the HPV virus, in- crease awareness about the HPV vaccine, overcome barriers to the HPV vaccine, and help adolescents and young adults make informed decisions to get the HPV vaccine. The research questions that guided the research agenda are as follows:

- R01: How knowledgeable are college students of the HPV virus?

- R02: What are the beliefs and attitudes of college students toward the HPV vaccine?

- R03: What barriers exist for college students preventing uptake of the HPV vaccine?

- R04: What digital health platforms (channels) would college students prefer to receive information about the risk of the HPV virus?

\section{Methodology \\ Sample}

The study was conducted among both male and female undergraduate and graduate students at a large public university in North Florida. Similar to other interventions focused on college students, they were selected as the study participants because of their constant exposure to the internet and technology. As Patel et al. ${ }^{23}$ explains, research should find ways "to implement HPV interventions via technologies acceptable to college students (e.g., text messaging, e-mail, social networking

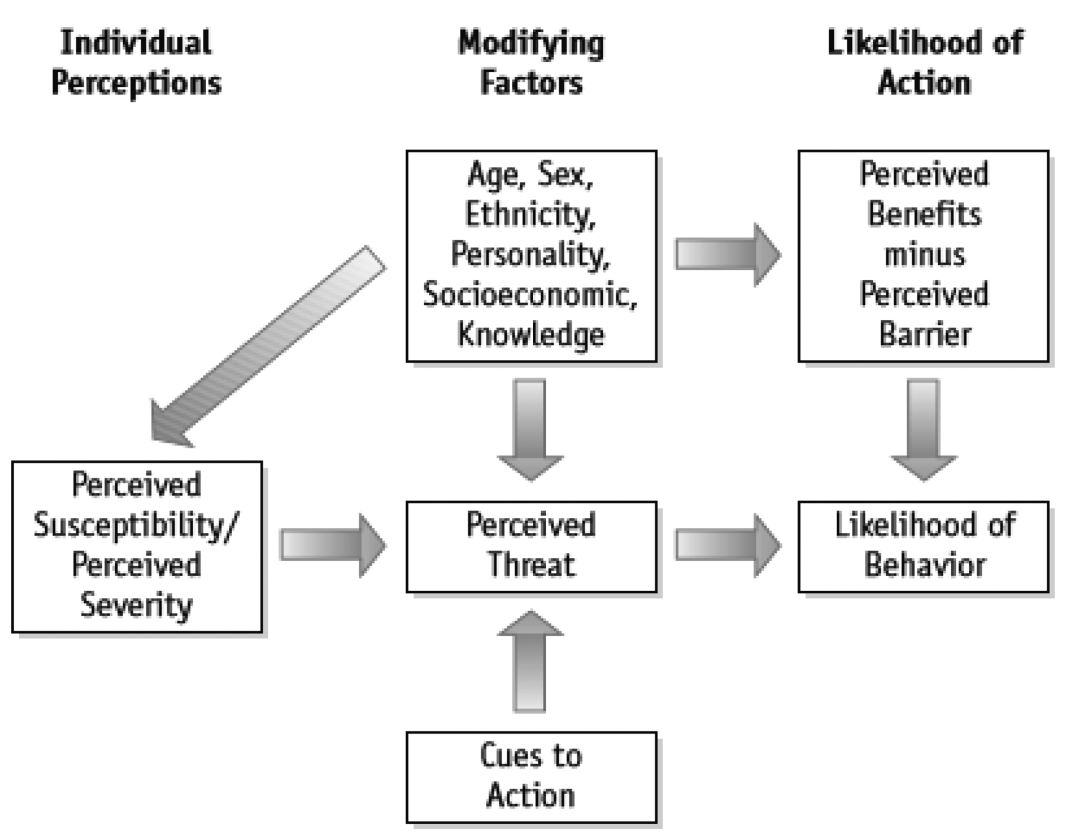

FIG. 1. Health belief model. 
media) etc." as it could improve the efficacy of interventions aimed at this population. ${ }^{23}$ Quantitative data on the survey included questions that asked about demographic characteristics, sexual health behaviors, knowledge of HPV, barriers to HPV uptake, and digital health technology practices.

\section{Procedure}

After Institutional Review Board approval was obtained, faculty of undergraduate and graduate courses in the Department of Health Education and Behavior were contacted and data collection was conducted with this convenience sample. Because of the descriptive nature of the survey, no inclusion and exclusion criteria were established. The survey was implemented using online software. Before data collection, the survey was pilot tested with a sample of undergraduate and graduate students $(n=81)$. Feedback provided from this sample was used to revise the survey for data collection, which was conducted over a period of 6 months.

Study participants were provided with an electronic link of the survey from their faculty. This link also included an inform consent page, which provided a disclaimer informing them of the sexual nature of the questions and listed on campus resources should they need to discuss any concerns they may have. Once consent was electronically obtained, participants were promoted to begin the survey. No incentives were offered by researchers for participating in the survey, however, faculty of the courses could offer extra credit if they chose to do so.

\section{Survey instrument}

Using validated and reliable scales found in HPV risk perception research ${ }^{11,24-26}$ and questions about technology use and digital health practices from Pew Research Center's Mobile Health, Health Tracking and Social Media Update Surveys, ${ }^{27-29}$ researchers developed a 54-item questionnaire, the Digital Health Solutions for Informed Decision Survey. Participants could differ in their number of responses per question. Multiple responses were possible. Participants could also decline to answer any question to which they did not want to answer.

Apart from demographical information, students provided answers to items that asked about their sexual activity behavior, sexual intercourse engagement, current sexual activity, number of sexual partners in the past 30 days, total number of lifetime partners, type of sexual activity ever engaged in, contraception use, condom use, gender of all sexual partners, history of sexually transmitted disease (STD) or HPV diagnosis, and HPV vaccination practices. Students answered questions concerning HPV knowledge, sources used to obtain HPV information, and beliefs regarding HPV. Their beliefs as it relates to cancer and HPV vaccination were measured, for this population used the Health Belief Scale, which included dimensions on four constructs of the HBM (perceived severity, perceived susceptibility, perceived benefits, and perceived barriers).

Students were also provided a list of frequently cited barriers throughout HPV literature and asked to select all that apply to them. Lastly, items included questions that also asked about smartphone ownership, smart phone usage, tracking devices/application use, types of health apps, digital health information practices, social media channel frequency use and access routes, SMS health messages, preference of channel to receive information, comfortableness using these digital technologies for HPV and HPV vaccine information, and interest in receiving information through SMS text message or mobile apps. Within this questionnaire, there were several questions included, an "other" response item, to allow participants the opportunity to provide information if the best response was not listed.

\section{Data analysis}

Descriptive statistics (means and frequencies) were calculated for the measures. Because researchers used previously validated and reliable scale items identified in literature, Cronbach' alpha was not calculated for the purpose of this research study.

\section{Results}

Although 210 participants contributed to this research study, survey responses varied for each section of questions as some questions included missing data. All results collected are reported in Tables 1-8. Male and female study participants completed the selfadministered survey (Table 1). Demographic characteristics identified that the majority of the population was $18-25$ years old $(n=147 ; 88 \%)$, female $(n=143$; $85.6 \%)$, not of Hispanic origin $(n=136 ; 64.8 \%)$, White/Caucasian $(n=126 ; 60 \%)$, upperclassman and seniors $(n=103 ; 61.6 \%)$, went to school fulltime $(n=154 ; 92.2 \%)$, were Florida residents $(n=161$; 97.6\%), and had private health insurance through their parents $(n=122 ; 73.1 \%)$. The majority of the survey respondents were citizens of the United States (Table 1). 
Table 1. Demographic Variables, Frequency, and Percent

\begin{tabular}{|c|c|c|c|c|c|}
\hline Descriptive variables & Frequency $(n)$ & ) Valid percent (\%) & Descriptive variables & Frequency $(n)$ & Valid percent (\%) \\
\hline Age (years) & & & Classification & & \\
\hline $18-25$ & 147 & 88 & Freshman (1st year) & 33 & 19.8 \\
\hline $26-34$ & 14 & 8.4 & Sophomore (2nd year) & 21 & 12.6 \\
\hline $35-54$ & 4 & 2.0 & Upperclassman (3rd year) & 61 & 36.5 \\
\hline $45-54$ & 1 & 0.6 & Senior (4th + year) & 42 & 25.1 \\
\hline $55-64$ & 1 & 0.6 & Graduate student & 10 & 6.0 \\
\hline Total & 167 & 100 & Total & 167 & 100 \\
\hline Gender & & & Student status & & \\
\hline Male & 24 & 14.4 & Part-time & 13 & 7.8 \\
\hline Female & 143 & 85.6 & Full-time & 154 & 92.2 \\
\hline Total & 167 & 100 & Total & 167 & 100 \\
\hline *Ethnicity (check all that apply) & & & Health insurance & & \\
\hline Not of Hispanic, Latino (a) or Spanish Origin & 136 & 81 & Private through parents & 122 & 73.1 \\
\hline Puerto Rican & 7 & 4.0 & Work or University Insurance & 21 & 12.6 \\
\hline Cuban & 4 & 2.0 & Public or other insurance & 16 & 9.6 \\
\hline Another Hispanic, Latino, or Spanish Origin & 15 & 8.9 & None or not sure & 8 & 4.8 \\
\hline Do not wish to respond & 7 & 4.0 & Total & 167 & 100 \\
\hline Total & 169 & 100 & Nationality/citizenship & & \\
\hline \multicolumn{6}{|l|}{ *Race (check all that apply) } \\
\hline Black or African American & 14 & 8 & & & \\
\hline White or Caucasian & 126 & 75 & Canada & 1 & 0.6 \\
\hline Asian Indian & 5 & 3 & China & 2 & 1.2 \\
\hline Chinese & 4 & 2 & Honduras & 1 & 0.6 \\
\hline Filipino & 9 & 5 & Malaysia & 1 & 0.6 \\
\hline Korean & 4 & 2 & Pakistan & 1 & 0.6 \\
\hline Vietnamese & 3 & 2 & Peru & 1 & 0.6 \\
\hline Do not wish to respond & 6 & 4 & Romania & 1 & 0.6 \\
\hline Total & 171 & 100 & United Kingdom & 1 & 0.6 \\
\hline Residency (where do you currently live?) & & & United States & 157 & 94 \\
\hline California & 1 & 0.6 & Vietnam & 1 & 0.6 \\
\hline Florida & 161 & 97.6 & Total & 167 & 100 \\
\hline Georgia & 1 & 0.6 & & & \\
\hline New York & 1 & 0.6 & & & \\
\hline Texas & 1 & 0.6 & & & \\
\hline Total & 165 & 100 & & & \\
\hline
\end{tabular}

*Note: One or more categories could be selected.

Before answering specific questions related to sexual practices and behavior, HPV risk perception, HPV vaccine beliefs and knowledge, and technology behavior, study participants were asked whether the HPV vaccine should be mandatory for children ages 9-12 years. Overwhelmingly, $74 \%$ of students $(n=144)$ out of 195 total responses indicated that the vaccine should be mandatory for adolescent-aged children. Reasons for making HPV vaccinations mandatory at that age are highlighted in the direct quotes noted below:

Participant 1: "The age range was chosen because it is a time before a child's first encounter of sexual intercourse and exposure to HPV. With that being the case, it serves as a great preventative measure for children and I think that it would only benefit the population if it is mandatory. However, I do feel that there should be exceptions to the requirement for those who would not benefit from the vaccine."
Participant 2: "Because the age kids are still in the routine of getting vaccinated."

Participant 3: "To children it is just another shot, however it can save their lives in the future. Even if the children do not grow up to be sexually active, it is at least a precaution."

Participant 4: "I think it should be mandatory because taking the vaccine during the best immune response time would likely have a significant impact on public health outcomes, and although one concern parents may have is that it might encourage an earlier age of initiation for sexual activity, I don't think those two factors are necessarily related since young children don't need to know that the vaccine is for an STI. Being protected from one STI should not be an enabling factor for unsafe sex if there is proper sex education involved (which there always should be)." 
Table 2. Sexually Transmitted Diseases and Human Papillomavirus Diagnoses/Vaccine: Frequency and Percent

\begin{tabular}{|c|c|c|}
\hline & $\begin{array}{l}\text { Frequency } \\
\quad(n)\end{array}$ & $\begin{array}{l}\text { Valid percent } \\
(\%)\end{array}$ \\
\hline \multicolumn{3}{|l|}{ STD diagnoses } \\
\hline Yes & 19 & 9.7 \\
\hline No & 177 & 90.3 \\
\hline Total & 196 & 100 \\
\hline \multicolumn{3}{|l|}{ HPV diagnoses } \\
\hline Yes & 14 & 7.1 \\
\hline No & 182 & 92.9 \\
\hline Total & 196 & 100 \\
\hline \multicolumn{3}{|l|}{ HPV vaccine received } \\
\hline No & 33 & 17.3 \\
\hline $\begin{array}{l}\text { No, I am outside of the recommended } \\
\text { age } \\
\text { range }\end{array}$ & 11 & 5.8 \\
\hline $\begin{array}{l}\text { Yes, I have already completed the } \\
\text { vaccine } \\
\text { series }\end{array}$ & 119 & 62.3 \\
\hline $\begin{array}{l}\text { Yes, I have started the vaccine series } \\
\text { (three } \\
\text { shots) and intend to complete it }\end{array}$ & 14 & 7.3 \\
\hline $\begin{array}{l}\text { Yes I have started the vaccine and DO } \\
\text { NOT } \\
\text { intend to complete it }\end{array}$ & 6 & 3.1 \\
\hline $\begin{array}{l}\text { Do not know my HPV vaccination } \\
\text { status }\end{array}$ & 8 & 4.2 \\
\hline Total & 191 & 100 \\
\hline \multicolumn{3}{|l|}{ Received doses of the HPV vaccine } \\
\hline 1 dose & 7 & 3.7 \\
\hline 2 doses & 16 & 8.4 \\
\hline All 3 doses & 117 & 61.6 \\
\hline None & 40 & 21.1 \\
\hline $\begin{array}{l}\text { Do not know my HPV vaccination } \\
\text { status }\end{array}$ & 10 & 5.3 \\
\hline Total & 190 & 100 \\
\hline
\end{tabular}

HPV, human papillomavirus; STD, sexually transmitted disease.

Variables of interest

Responses to STD/HPV vaccine and sexual history behaviors can be found in Tables 1 and 2. Majority of the sample was reproductive age non-Hispanic women (Table 1). Greater than $90 \%$ of the study sample self-reported no history of STDs and no history of HPV (Table 2). Greater than $62 \%$ received three doses of HPV vaccine. Table 3 highlights the level of HPV awareness and knowledge among our study population. Areas of concern, and questions answered incorrectly included: you get HPV for life, and condoms protect against HPV infection. Safety appears to be a concern for about half of the study population, $51 \%$ do not have confidence that the HPV vaccine is safe, and $47 \%$ believe the HPV vaccine is harmful (Table 4). Study participants in our sample were queried in greater detail about their beliefs and were asked to indicate their level of agreement concerning 14 statements related to key barriers to HPV vaccine uptake. Lack of information and knowledge about HPV or HPV vaccine was identified as a barrier to HPV uptake (Table 5).

Information concerning study sample current digital health technology practices were queried (Table 6). Most used smartphones to access social media several times a day (Table 7). Facebook was the highest social media trend $(\sim 76 \%)$ followed by Instagram $(68 \%)$ and LinkedIn not being used often (7\%; Table 6). When asked about the preferred digital health technologies to communicate about HPV risk and vaccine, the preferred platform was identified as internet or online website. Receiving text messages about HPV was not popular, only 29\% were interested in receiving health-related text. Comfort with using various health channels to receive HPV vaccine information was low for social network sites (22\%), and digital gaming (13.5\%; Table 8$)$.

\section{Discussion}

Evidence was explored to support strategies to facilitate digital health technologies aimed at increasing risk perception of the HPV virus and awareness of the HPV vaccine. The preferred method of communication by college students to communicate HPV risk and

Table 3. Human Papillomavirus Knowledge Among College Students

\begin{tabular}{|c|c|c|c|}
\hline HPV knowledge & Total & Correct answer $(n)$ & Valid percentage $(\%)$ \\
\hline 1. People with certain HPV types always develop health problems. (False) & 185 & 136 & 73.5 \\
\hline 2. Women can get HPV. (True) & 185 & 184 & 99.5 \\
\hline 3. Condoms effectively protect against HPV infection. (False) & 185 & 82 & 44.3 \\
\hline 4. HPV may spread from person to person by sexual intercourse. (True) & 185 & 185 & 100 \\
\hline 5. Males may be infected with HPV and not know it. (True) & 185 & 180 & 97.3 \\
\hline 6. HPV infection can be cured with antibiotics. (False) & 185 & 155 & 83.8 \\
\hline 7. Men can get HPV. (True) & 185 & 181 & 97.8 \\
\hline 8. If you get HPV, you will have HPV for life. (False) & 185 & 49 & 26.5 \\
\hline 9. Females may be infected with HPV and not know it. (True) & 185 & 183 & 98.9 \\
\hline 10. A person can get HPV by having sex. (True) & 185 & 185 & 100 \\
\hline 11. HPV infection among women is rare. (False) & 185 & 177 & 95.7 \\
\hline 12. Condoms always protect you from HPV. (False) & 185 & 177 & 95.7 \\
\hline 13. HPV may be spread from person to person through oral sex. (True) & 184 & 169 & 91.8 \\
\hline 14. HPV infection among men is rare. (False) & 184 & 145 & 78.8 \\
\hline
\end{tabular}


Table 4. Beliefs Statements: Human Papillomavirus Vaccine by Level of Agreement

\begin{tabular}{|c|c|c|c|c|c|c|}
\hline & & Strongly disagree & Disagree & $\begin{array}{l}\text { Neither agree } \\
\text { or disagree }\end{array}$ & Agree & Strongly agree \\
\hline Belief statement & Total & $n(\%)$ & $n(\%)$ & $n(\%)$ & $n(\%)$ & $n(\%)$ \\
\hline I do not believe in vaccinations generally. & 176 & $122(69.3)$ & $39(22.2)$ & $11(6.3)$ & $3(1.7)$ & $1(0.6)$ \\
\hline Vaccinations are not effective and do not prevent diseases. & 176 & $132(75)$ & $34(19.3)$ & $10(5.7)$ & $0(0)$ & $0(0)$ \\
\hline It is not important to receive all vaccinations. & 176 & $101(57.4)$ & $42(23.9)$ & $17(9.7)$ & $8(4.5)$ & $8(4.5)$ \\
\hline $\begin{array}{l}\text { It is preferable to get the diseases and be protected naturally than } \\
\text { to vaccinate. }\end{array}$ & 176 & $118(67.0)$ & $40(22.7)$ & $16(9.1)$ & $1(0.6)$ & $1(0.6)$ \\
\hline I do not have confidence that the HPV vaccine is safe. & 176 & $90(51.1)$ & $43(24.4)$ & $28(15.9)$ & $12(6.8)$ & $3(1.7)$ \\
\hline $\begin{array}{l}\text { I believe if I receive the HPV vaccine, I will not be protected } \\
\text { from cervical cancer (anal/penile cancer if male). }\end{array}$ & 175 & $71(40.6)$ & $56(32.0)$ & $35(20)$ & $11(6.3)$ & $2(1.1)$ \\
\hline $\begin{array}{l}\text { I believe that if I receive the HPV vaccine, I will not be protected } \\
\text { against HPV. }\end{array}$ & 176 & $80(45.5)$ & $63(35.8)$ & $23(13.1)$ & $6(3.4)$ & $4(2.3)$ \\
\hline I do not have enough information about HPV. & 176 & $38(21.6)$ & $37(21.0)$ & $36(20.5)$ & $57(32.4)$ & $8(4.5)$ \\
\hline I do not have enough information about the HPV vaccine. & 176 & $43(24.4)$ & $37(21.0)$ & $36(20.5)$ & $51(29.0)$ & $9(5.1)$ \\
\hline Cost would influence my uptake of the HPV vaccine. & 176 & $54(30.7)$ & $40(22.7)$ & $28(15.9)$ & $39(22.2)$ & $15(8.5)$ \\
\hline $\begin{array}{l}\text { My insurance/health care provider did not allow me to receive } \\
\text { the vaccine. }\end{array}$ & 176 & $87(49.4)$ & $39(22.2)$ & $48(27.3)$ & $1(0.6)$ & $1(0.6)$ \\
\hline I did/do not have money for vaccination. & 176 & $78(44.3)$ & $52(29.5)$ & $34(19.3)$ & $9(5.1)$ & $3(1.7)$ \\
\hline My sexual behavior is safe. & 176 & $6(3.4)$ & $11(6.3)$ & $28(15.9)$ & $63(35.8)$ & $68(38.6)$ \\
\hline I do not believe that HPV is exceptionally harmful. & 176 & $94(53.4)$ & $51(29.0)$ & $14(8.0)$ & $12(6.8)$ & $5(2.8)$ \\
\hline
\end{tabular}

vaccine was internet or online websites. Strategy, use of the internet, mobile phones, SMS test messages, and mobile apps to help disseminate evidence-based HPV and HPV vaccination information to adolescents and college students was explored. Currently, most college students reported not receiving text messages from health care providers as updated to health care or messages on the HPV virus. In this study, electronic surveys explored preferred digital health technologies in addition to HPV knowledge, individual risk perception, and awareness of the HPV vaccine. The HPV vaccine was approved for use in boys in 2011 and girls in 2006. Knowledge and awareness of HPV and HPV vaccine were significant and high among our study participants. The majority of the study participants were within the age group of HPV vaccination recommendation (i.e., 18-26 years) and eligible to remain on their parent's insurance plans. Nationally, $63 \%$ of girls and $50 \%$ of boys have received at least one dose of HPV vaccine and $\sim 33 \%$ completed the series. ${ }^{20}$

The HPV vaccination rate for our sampled population was 7.3\% $(n=14)$ for starting the series, $62.3 \%(n=119)$ for completing the vaccine series, and 3.1\% $(n=6)$ for not intending to complete the vaccine. Another small percent/population, $4.2 \%(n=8)$, reported not knowing if they were vaccinated against HPV. Adolescent are not always aware of which vaccine was received since this is under the control of their parents' consent, may have been bundled with other required school-age vaccinations. Our completion rate is higher than the national average. The vaccine is currently a two-dose regimen, a shift from a three-dose regimen in 2016 offering protection to those not completing the HPV vaccine series. Specifically, a two-dose regimen is recommended for girls and boys starting the HPV series at ages 9 through 14 years, and three doses remain for boys and girls starting the HPV series at ages 15 through 26 years. Among our study participants, vaccination rates were not separated by gender; the study population was largely $(85.6 \%)$

Table 5. Barriers to Human Papillomavirus Vaccine Uptake

\begin{tabular}{|c|c|c|}
\hline Barrier (s) & $\begin{array}{l}\text { Frequency } \\
\qquad(n)\end{array}$ & $\begin{array}{l}\text { Percent } \\
\text { (\%) }\end{array}$ \\
\hline 1. Safety/long-term side effects of the vaccine & 22 & 10.5 \\
\hline 2. Cost/vaccine not covered by health insurance & 32 & 15.2 \\
\hline 3. Vaccine is painful/discomfort with injection & 13 & 6.2 \\
\hline $\begin{array}{l}\text { 4. Vaccine coverage (not preventing all HPV } \\
\text { strains or all STIs) }\end{array}$ & 10 & 4.8 \\
\hline 5. Not at risk or low risk for HPV & 24 & 11.4 \\
\hline 6. Not a priority & 25 & 11.9 \\
\hline 7. Access to health care provider & 8 & 3.8 \\
\hline $\begin{array}{l}\text { 8. Embarrassed, self-conscious, or } \\
\text { uncomfortable talking to health care } \\
\text { provider }\end{array}$ & 7 & 3.3 \\
\hline $\begin{array}{l}\text { 9. Lack of information and knowledge about HPV } \\
\text { or HPV vaccine }\end{array}$ & 34 & 16.2 \\
\hline $\begin{array}{l}\text { 10. Parental influence in decision-making process } \\
\text { (i.e., mother/parents advised not to obtain } \\
\text { the vaccine) }\end{array}$ & 23 & 11.0 \\
\hline 11. Have already been diagnosed with HPV & 7 & 3.3 \\
\hline 12. Never had sexual intercourse & 13 & 6.2 \\
\hline $\begin{array}{l}\text { 13. Current contraception practices are } \\
\text { sufficient for protection against HPV }\end{array}$ & 3 & 1.4 \\
\hline 14. Outside the recommended age group & 14 & 6.7 \\
\hline 15. Other & 8 & 3.8 \\
\hline 16. Not applicable, I already got the vaccine & 104 & 49.5 \\
\hline
\end{tabular}

Note: $N=210$.

STI, sexually transmitted infection 
Table 6. Current Social Media Usage Trends Among College Students $(N=\mathbf{2 1 0})$

\begin{tabular}{lccrr}
\hline Social media use & Smartphone, $\boldsymbol{n}$ (\%) & Tablet, $\boldsymbol{n}(\%)$ & Computer, $\boldsymbol{n}(\%)$ & Do not use, $\boldsymbol{n}(\%)$ \\
\hline Facebook & $159(75.7)$ & $42(20 \%)$ & $144(68.6)$ & $7(3.3)$ \\
Instagram & $142(67.6)$ & $15(7.1)$ & $24(11.4)$ & $26(12.4)$ \\
Linkedln & $14(6.7)$ & $5(2.4)$ & $29(13.8)$ & $80(38.1)$ \\
Pinterest & $78(37.1)$ & $20(9.5)$ & $31(14.8)$ & $56(26.7)$ \\
Twitter & $70(33.3)$ & $11(5.2)$ & $7(3.3)$ & $86(41.0)$ \\
Other & $16(7.6)$ & $1(0.5)$ & $70(33.3)$ \\
\hline
\end{tabular}

Note response range: several times a day, once a day, three times a week, 1-2 days a week, every few weeks, less often, I do not use.

female. Knowledge with regard to required immunization may be higher for college students due to vaccination college entrance requirements. ${ }^{30}$ The American College Health Association guidelines requirements for vaccinepreventable diseases policy implementations found that the immunization compliance rate among colleges were about $93 \%$ among sampled colleges. ${ }^{30}$

This study occurred in a state with requirements for some vaccination; Florida does no mandate HPV vaccination. A large majority of our sample $(74 \%)$ of the younger age group held the belief of HPV vaccine being mandatory for children ages 9-12 years. This majority also strongly disagreed with statements that went against the importance of vaccinations. This could be a positive predictor of support of childhood vaccination for our future generation of parents.

Due to the immune system, HPV has a higher clearance rate among younger age. But a greater propensity for disease due to lower immune system has been reported with increasing age. The small percentage of 7.1\% reported ever having a positive HPV diagnosis supports national guidelines indicating that HPV screening should not occur until age 30 years and above. The 26 years and older age group was more likely to agree with the statement that HPV was not harmful. This finding may indicate a need for greater health education regarding HPV and HPV vaccination. As reported in two studies, there was a significant relationship between receiving health information through technology and age.

Younger study participants were more likely to want HPV information through technology when compared with older study participants. ${ }^{31,32}$ Digital health technol- ogy can be cost effective and easily evaluated for effectiveness in facilitating HPV knowledge and immunization uptake. Opportunities to design age- and populationspecific education interventions has a role in digital technology health information dissemination.

\section{Conclusion and Future Implications}

Research findings supporting digital technology platforms to disseminate evidence-based HPV data and HPV vaccination educational information targeting adolescents and young adults in academic and other setting can help health care providers make informed decisions about age-appropriate, topic, and content-relevant information specifically targeting this population. The findings of this study indicated that work is needed in the acceptance of social media, SMS text messaging, and mobile Apps as preferred digital health technologies beyond the internet. Health care providers can educate parents and students with regard to navigating the health system to obtain health information by using text messages and mobile apps, easily and effectively. Electronic health records, patient portals, and local health departments are all possible repositories of vaccine information/status. Taking advantage of patient encounters, such as annual Well-Women Visits, provide opportune time to screen for STDs, update vaccinations, and provide sexual and reproductive health education. For example, Chlamydia is the most common reportable STD in the United States. HPV is the most common STD in women. Populations most burdened by STDs are adolescents and young adults ages 15-24 years. As per the CDC national guidelines, sexually active women under the age of 25 years

Table 7. Current Social Media Visit Frequencies Among College Students

\begin{tabular}{|c|c|c|c|c|c|c|}
\hline Frequency of visiting social media site & Facebook, $n(\%)$ & Instagram, $n(\%)$ & Linkedln, $n(\%)$ & Pinterest, $n(\%)$ & Twitter, $n$ (\%) & Other, $n(\%)$ \\
\hline Several times a day & $124(59)$ & $113(53.8)$ & $1(0.5)$ & $17(8.1)$ & $34(16.2)$ & $12(5.7)$ \\
\hline About once per day & $27(12.9)$ & $17(8.1)$ & $5(2.4)$ & $13(6.2)$ & $10(4.8)$ & $2(1.0)$ \\
\hline 3-5 times a week & $6(2.9)$ & $8(3.8)$ & $2(1.0)$ & $16(7.6)$ & $8(3.8)$ & $0(0)$ \\
\hline $1-2$ days a week & $3(1.4)$ & $1(0.5)$ & $5(2.4)$ & $19(9.0)$ & $4(1.9)$ & $2(1.0)$ \\
\hline Every few weeks & $2(1.0)$ & $3(1.4)$ & $12(5.7)$ & $25(11.9)$ & $8(3.8$ & $1(0.5)$ \\
\hline Less often & $1(0.5)$ & $13(6.2)$ & $19(9.0)$ & $19(9.0)$ & $13(6.2)$ & $0(0)$ \\
\hline I do not use & $7(3.3)$ & $30(14.3)$ & $123(58.6)$ & $58(27.6)$ & 88 (41.9) & $107(51)$ \\
\hline
\end{tabular}


Table 8. Preferred Digital Health Technologies by College Students to Communicate About Human Papillomavirus (HPV) Risk and the HPV Vaccine

\begin{tabular}{|c|c|c|}
\hline Characteristics & $\begin{array}{l}\text { Frequency } \\
\text { (n) }\end{array}$ & $\begin{array}{l}\text { Valid } \\
\text { percent } \\
(\%)\end{array}$ \\
\hline \multicolumn{3}{|c|}{ Channel/platform preferred to receive information about HPV risk } \\
\hline Internet or online website & 127 & 73.8 \\
\hline Social media & 11 & 6.4 \\
\hline Mobile app & 18 & 10.5 \\
\hline SMS text messages & 13 & 7.6 \\
\hline Digital games & 3 & 1.7 \\
\hline Total & 172 & 100 \\
\hline \multicolumn{3}{|c|}{ Do you receive text message updates from your health care provider } \\
\hline Yes & 51 & 29.3 \\
\hline No & 123 & 70.7 \\
\hline Total & 174 & 100 \\
\hline \multicolumn{3}{|c|}{ Interest in receiving health-related text messages on the HPV virus } \\
\hline Yes & 51 & 29.7 \\
\hline No & 121 & 70.3 \\
\hline Total & 172 & 100 \\
\hline \multicolumn{3}{|c|}{ Interest in receiving health-related text messages on the HPV vaccine } \\
\hline Yes & 41 & 23.8 \\
\hline No & 131 & 76.2 \\
\hline Total & 172 & 100 \\
\hline \multicolumn{3}{|c|}{$\begin{array}{l}\text { Frequency of SMS text messages on HPV (risk factors, vaccine information, } \\
\text { local resources, and health care provider info) }\end{array}$} \\
\hline Once per week & 42 & 25 \\
\hline Every other day & 1 & 0.6 \\
\hline Set my own schedule/frequency & 36 & 21.4 \\
\hline None, I do not want to receive text messages & 89 & 53 \\
\hline Total & 168 & 100 \\
\hline \multicolumn{3}{|c|}{ Information to be included in SMS text messaging on the HPV vaccine } \\
\hline The safety of the vaccine & 67 & 31.9 \\
\hline Insurance plans that cover the vaccine & 48 & 22.9 \\
\hline $\begin{array}{l}\text { Realistic expectations of discomfort of the } \\
\text { vaccine }\end{array}$ & 51 & 24.3 \\
\hline The effectiveness of the vaccine & 78 & 37.1 \\
\hline College student's risk of acquiring HPV & 69 & 32.9 \\
\hline $\begin{array}{l}\text { How to talk to a health care provider about } \\
\text { acquiring the HPV vaccine }\end{array}$ & 30 & 14.3 \\
\hline $\begin{array}{l}\text { How to access information and knowledge } \\
\text { about HPV and the HPV vaccine }\end{array}$ & 51 & 24.3 \\
\hline $\begin{array}{l}\text { How to talk to your parents about sex and } \\
\text { the importance of receiving the HPV } \\
\text { vaccine }\end{array}$ & 19 & 9.0 \\
\hline $\begin{array}{l}\text { Measures that college students already } \\
\text { diagnosed with HPV can take to manage } \\
\text { their condition }\end{array}$ & 44 & 21.0 \\
\hline $\begin{array}{l}\text { How college students can negotiate using } \\
\text { contraception practices that provide } \\
\text { protection against HPV with your partner }\end{array}$ & 33 & 15.7 \\
\hline Other & 1 & 0.5 \\
\hline None, I do not want to receive text messages & 91 & 43.3 \\
\hline \multicolumn{3}{|c|}{ Interest in using an "app" on smartphone on HPV or the HPV vaccine } \\
\hline Yes & 59 & 34.9 \\
\hline No & 110 & 65.1 \\
\hline Total & 169 & 100 \\
\hline \multicolumn{3}{|c|}{ Likeliness to use a health-related app for HPV and the HPV vaccine } \\
\hline Very unlikely & 57 & 33.9 \\
\hline Unlikely & 28 & 16.7 \\
\hline Somewhat unlikely & 18 & 10.7 \\
\hline Undecided & 16 & 9.5 \\
\hline Somewhat likely & 28 & 16.7 \\
\hline Likely & 17 & 10.1 \\
\hline Very likely & 4 & 2.4 \\
\hline Total & 168 & 100 \\
\hline
\end{tabular}

Note: Preference ranged from $1=$ internet/online website; $2=$ socia media; $3=$ mobile apps; $4=$ SMS text messages; $5=$ digital games.

SMS, short message service. should be screened for gonorrhea, an opportune time to discuss HPV and HPV vaccination. ${ }^{1}$ HPV testing is not recommended in this age group, not until 30 years of age. ${ }^{33}$ However, CDC, Association of American Cancer Institutes, and American Cancer Society-leaders in HPV cancer prevention-have partnered to establish an HPV Vaccination Champion to reinforce that HPV Vaccine is Cancer Prevention. ${ }^{34}$

The HPV Vaccination Roundtable is one such Vaccine Champion developing the campaign "We're In!" a Facebook profile picture frame. ${ }^{34}$ Facebook picture frames are a way individuals can demonstrate support for HPV vaccination as cancer prevention. ${ }^{34}$ Facebook is one of many digital health platforms providing evidence-based health information similar to Twitter, Instagram, Google+, Vimeo, YouTube, Digg, Flikr, and Pinterest. Internet or online websites are the preferred digital health technologies for these study populations. Growing evidence support using digital health technologies to inform decision making to increase HPV risk perception and promote HPV vaccine uptake among adolescents and young adults. Digital health technology beyond the internet and online websites is warranted and when used appropriately can be a strategic and successful tool to inform decision making, increase perception, and promote HPV vaccine uptake. Text messaging can be used to receive updates from healthcare providers.

\section{Author Disclosure Statement}

The authors have no commercial association to disclose that may create a conflict of interest in connection with the submitted manuscript.

\section{References}

1. Centers for Disease Control and Prevention. Genital HPV infection-Fact sheet. 2017. https://www.cdc.gov/std/hpv/stdfact-hpv.htm Accessed May 9, 2019.

2. World Health Organization. World health statistics. 2010. www.who.int/ gho/publications/world_health_statistics/EN_WHS10_Full.pdf Accessed May 9, 2019.

3. Markowitz LE, Dunne EF, Saraiya M, et al. Human papillomavirus vaccination: recommendations of the Advisory Committee on Immunization Practices (ACIP). MMWR Recomm Rep. 2014;63:1-30.

4. President's Cancer Panel. Accelerating HPV vaccine update: urgency for action to prevent cancer. 2013. https://deainfo.nci.nih.gov/advisory/pcp/ annualreports/hpv/index.htm Accessed August 8, 2017.

5. Food and Drug Administration. FDA approves expanded use of Gardasil 9 to include individuals 27 through 45 years old. FDA.gov press release. October 5, 2018. www.fda.gvo/newsevents/newsroom/ pressannouncements/ucm622815 Accessed May 10, 2019.

6. Head KJ, Biederman E, Sturm LA, et al. A retrospective and prospective look at strategies to increase adolescent HPV vaccine uptake in the United States. Hum Vaccin Immunother. 2018;14:1626-1635.

7. U.S. Department of Health and Human Services. Healthy people 2020: immunization and infectious diseases. October 2017. https:// www.healthypeople.gov/2020/topics-objectives/topic/immunizationand-infectious-diseases Accessed August 8, 2017. 
8. Daley EM, Vamos CA, Zimet GD, et al. The feminization of HPV: reversing gender biases in US human papillomavirus vaccine policy. Am J Public Health. 2016;106:983-984.

9. Vielot NA, Butler AM, Brookhart MA, et al. Patterns of use of human papillomavirus and other adolescent vaccines in the United States. J Adolesc Health. 2017;61:281-287.

10. Thompson EL, Rosen BL, Vamos CA, et al. Human papillomavirus vaccination: what are the reasons for non vaccination among US adolescents? J Adolesc Health. 2017;61:288-293.

11. Katz ML, Krieger JL, Roberto AJ. Human papillomavirus (HPV): college male's knowledge, perceived risk, sources of information, vaccine barriers and communication. J Mens Health. 2011;8:175-184.

12. Ventola CL. Immunization in the United States: recommendations, barriers, and measures to improve compliance: Part 1: Childhood vaccinations. P. T. 2016;41:426-436.

13. Lim MS, Hocking JS, Hellard ME, et al. SMS STI: a review of the uses of mobile phone text messaging in sexual health. Int J STD AIDS. 2008;19:287-290.

14. Smith A. Record shares of Americans now own smartphones, have home broadband. 2017. http://www.pewresearch.org/fact-tank/2017/01/12/ evolution-oftechnology Accessed May 9, 2019.

15. Kratzke C, Cox C. Smartphone technology and apps: rapidly changing health promotion. Int Electron J Health Educ. 2012;15:72-82.

16. Braaten KP, Laufer MR. Human papillomavirus (HPV), HPV-related disease, and the HPV vaccine. Rev Obstet Gynecol. 2008;1:2-10.

17. NCl. HPV and cancer. 2015. https://www.cancer.gov/about-cancer/ causes-prevention/risk/infectious-agents/hpv-fact-sheet Accessed May 9, 2019

18. Forman D, de Martel C, Lacey CJ, et al. Global burden of human papillomavirus and related diseases. Vaccine. 2012;30:F12-F23.

19. Meites E, Kempe A, Markowitz LE. Use of a 2-dose schedule for human papillomavirus vaccination-updated recommendations of the Advisory Committee on Immunization Practices. MMWR Morb Mortal Wkly Rep. 2016;65:1405-1408.

20. Reagan-Steiner S, Yankey D, Jeyarajah J, et al. National, regional, state, and selected local area vaccination coverage among adolescents aged 13-17 years-United States, 2015. MMWR Morb Mortal Wkly Rep. 2016;65: 850-858.

21. Bruni L, Diaz M, Barrionuevo-Rosas L, et al. Global estimates of human papillomavirus vaccination coverage by region and income level: a pooled analysis. Lancet Global Health. 2016;4:e453-e463.

22. Strecher VJ, Rosenstock IM. The health belief model. In: Cambridge Handbook of Psychology, Health and Medicine. Baum A, Newman S, Weinman J, McManus C, West R, (eds.) Cambridge University Press: United Kingdom; pp. 113-117; 1997.

23. Patel DA, Zochowski M, Peterman $S$, et al. Human papillomavirus vaccine intent and uptake among female college Students. J Am Coll Health. 2012;60:151-161.

24. Fontenot HB, Fantasia HC, Charyk A, et al. Human papillomavirus (HPV) risk factors, vaccination patterns, and vaccine perceptions among a sample of male college students. J Am Coll Health. 2014;62:186-192.

25. Marchand E, Glenn B, Bastani R. Low HPV vaccine coverage among female community college students. J Commun Health. 2012;37:1136-1144.
26. Donadiki EM, Jiménez-García R, Hernández-Barrera $V$, et al. Health belief model applied to non-compliance with HPV vaccine among female university students. Public Health. 2014;128:268-273.

27. Fox S, Duggan M. Tracking for health-health tracking survey 2012-topline questionnaire. January 2013. http://www.pewinternet.org/files/old-media// Files/Questionnaire/2013/Surveyquestionsandmethodology.pdf Accessed April 12, 2015

28. Fox S, Duggan M. Mobile health 2012-topline questionnaire. Novembe 2013. http://www.pewinternet.org/files/old-media//Files/Questionnaire/ 2012/PIP_MobileHealth2012_SurveyQuestions.pdf Accessed April 12, 2015.

29. Duggan M, Ellison NB, Lampe $C$, et al. Social media update 2014-topline questionnaire. January 2015. http://www.pewinternet.org/files/2015/01/ SurveyQuestions.pdf Accessed May 30, 2015.

30. Jewett A, Bell T, Cohen NJ, et al. US college and university student health screening requirements for tuberculosis and vaccine-preventable diseases. J Am Coll Health. 2016;64:409-415.

31. Francis DB, Cates JR, Wagner KPG, et al. Communication technologies to improve HPV vaccination initiation and completion: a systematic review. Patient Educ Couns. 2017;100:1280-1286.

32. L'Engle KL, Mangone ER, Parcesepe AM, et al. Mobile phone interventions for adolescent sexual and reproductive health: a systematic review. Pediatrics. 2016;138:e20160884.

33. Lee KC, Ngo-Metzger Q, Wolff T, et al. Sexually transmitted infections: recommendations from the US preventive services task force. Am Fam Phys. 2016;94:907-915.

34. Sienko J. "We're In": a communication showcase. National HPV Vaccination Roundtable. 2017. https://www.mysocietysource.org/sites/ RoundTable/HPV/Were\%20In\%20Documents/HPV\%20Vaccination\%20S ymbol_We'reln!.pdf Accessed September 14, 2017.

Cite this article as: Johnson-Mallard V, Darville G, Mercado R Anderson-Lewis C, Maclnnes J (2019) How health care providers can use digital health technologies to inform human papillomavirus (HPV) decision making and promote the HPV vaccine uptake among adolescents and young adults, BioResearch Open Access 8:1, 84-93, DOI: 10.1089/biores.2018.0051.

\section{Abbreviations Used}

$C D C=$ Centers for Disease Control and Prevention

$\mathrm{FDA}=$ Food and Drug Administration

$\mathrm{HBM}=$ health belief model

$\mathrm{HPV}=$ human papillomavirus

SMS $=$ short message service

STD $=$ sexually transmitted disease

$\mathrm{STI}=$ sexually transmitted infection

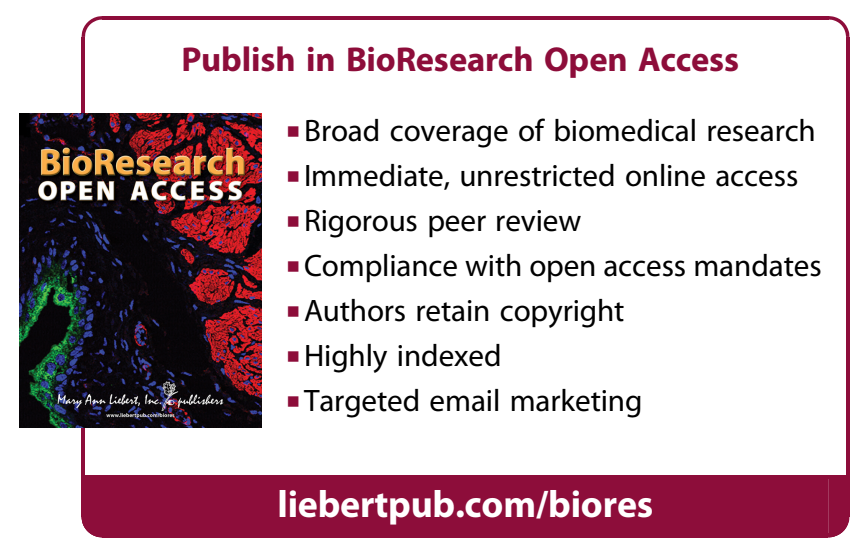

